\title{
Is there an association between daytime napping and cognitive function? A Mendelian randomisation study in the UK Biobank
}

\author{
Valentina Paz ${ }^{12}$, Hassan S. Dashti ${ }^{345}$, Victoria Garfield ${ }^{2}$
}

1. Department of Clinical Psychology, Facultad de Psicología, Universidad de la República, Montevideo, Uruguay.

2. MRC Unit for Lifelong Health \& Ageing, Institute of Cardiovascular Science, University College London, London, United Kingdom.

3. Center for Genomic Medicine, Massachusetts General Hospital and Harvard Medical School, Boston, MA, USA.

4. Broad Institute, Cambridge, MA, USA.

5. Department of Anesthesia, Critical Care and Pain Medicine, Massachusetts General Hospital and Harvard Medical School, Boston, MA, USA.

\section{Corresponding author:}

Valentina Paz

Tristan Narvaja 1674, Montevideo, Uruguay.

E-mail:vpaz@psico.edu.uy / v.paz@ucl.ac.uk 
medRxiv preprint doi: https://doi.org/10.1101/2021.09.28.21264215; this version posted September 29, 2021. The copyright holder for this preprint (which was not certified by peer review) is the author/funder, who has granted medRxiv a license to display the preprint in

It is made available under a CC-BY-NC-ND 4.0 International license.

\begin{abstract}
Background:

Daytime napping has been associated with cognitive function in observational studies. However, it remains elusive whether napping could be beneficial or detrimental for cognition and whether these associations are causal.
\end{abstract}

\title{
Methods:
}

Using Mendelian randomisation (MR), we studied the relationship between daytime napping and cognitive outcomes. Data were from UK Biobank $(n=378,932$; mean age $=57$ years $)$. Our exposure (daytime napping) was instrumented using 92 genome-wide, independent genetic variants and our cognitive outcomes were reaction time and visual memory. Inverse-variance weighted MR was implemented, with sensitivity analyses including MR-Egger and the Weighted Median Estimator for horizontal pleiotropy. We also tested different daytime napping instruments (47 SNPs, 86 SNPs and 17 SNPs) to ensure the robustness of our results.

\section{Results:}

No associations were found between daytime napping and reaction time $(\exp \beta=1.01$, $95 \% \mathrm{CI}=1.00 ; 1.03)$, or visual memory $(\exp \beta=0.99,95 \% \mathrm{CI}=0.94 ; 1.05)$. MR-Egger and Weighted Median Estimator approaches showed no evidence of horizontal pleiotropy. Additional analyses with 47 SNPs (adjusted for excessive daytime sleepiness), 86 SNPs (excluding sleep apnoea) and 17 SNPs (no sample overlap with UKB) also showed no associations with reaction time or visual memory.

\section{Conclusions:}

Overall, we observed no evidence of a causal association between habitual daytime napping and reaction time and visual memory. Future studies should focus on the associations between napping and other cognitive outcomes.

Keywords: Mendelian randomisation; Daytime napping; Cognitive function 
medRxiv preprint doi: https://doi.org/10.1101/2021.09.28.21264215; this version posted September 29, 2021. The copyright holder for this preprint (which was not certified by peer review) is the author/funder, who has granted medRxiv a license to display the preprint in

It is made available under a CC-BY-NC-ND 4.0 International license .

\section{Introduction}

Daytime napping, defined as brief daytime bouts of sleep [1], is a universal $[2,3]$ and highly prevalent behaviour [4], reported in approximately $30 \%$ of the British population [5]. Napping has been associated with multiple health outcomes [4,6], including cognitive function $[7,8]$. Interestingly, napping seems beneficial to performance on certain cognitive tasks $[3,9,10]$. These benefits arise immediately following a brief nap (e.g. 5-15 minutes) and can last between one to three hours. After a long nap ( $>30 \mathrm{~min})$, a temporary deterioration of performance emerges, followed by improvements that can last up to a day [10]. However, some authors argue that individuals who frequently have a nap and those who never nap may differ in the benefits derived from napping, with the latter experiencing no benefits from it [3]. While recently more attention has been paid to napping, it remains elusive whether habitual daytime napping could be beneficial or detrimental for cognition [11]. In addition, as most studies about the relationship between napping and cognitive function are observational, causal associations between both could not be drawn.

To overcome this limitation, Mendelian randomisation (MR) can be used, which is based on the analysis of genetic markers, to examine the possible causal associations between exposures and outcomes [12,13]. Previous MR studies investigated the causal relationship between sleep traits and cognitive outcomes. These studies reported that both short and long sleep duration are associated with poorer cognitive outcomes [14] and, short sleep is associated with Alzheimer's disease (AD) risk [15]. Regarding napping, Anderson et al. (2021) found suggestive evidence that self-reported habitual daytime napping is associated with lower AD risk. However, no previous MR studies investigated the association between daytime napping and cognitive outcomes. Given that the most pronounced decline during ageing occurs in reaction time and memory [17], and the high prevalence of cognitive impairment in the ageing population [18], the identification of modifiable risk factors is essential. Thus, the present study aimed to use MR to examine whether the relationship between daytime napping and cognitive function might be causal.

\section{Methods}

Sample

The UK Biobank (UKB) cohort has been described in detail elsewhere [19]. Briefly, UKB recruited 500,000 males and females from the general UK population, aged 40-69 years at baseline (2006-2010). Although UKB recruited participants of distinct ancestries, those 
medRxiv preprint doi: https://doi.org/10.1101/2021.09.28.21264215; this version posted September 29, 2021. The copyright holder for this preprint (which was not certified by peer review) is the author/funder, who has granted medRxiv a license to display the preprint in

It is made available under a CC-BY-NC-ND 4.0 International license .

included in this study were of white European ancestry and retained if they had relevant (quality-controlled) genotype and phenotype data $(\mathrm{N}=378,932)$.

\section{Study design}

Our exposure $\left(\mathrm{SNPs}_{\mathrm{x}}\right)$ sample overlapped with our outcome sample $\left(\mathrm{SNPs}_{\mathrm{y}}\right)$ by $77 \%$. This is because the discovery genome-wide association study (GWAS) for the exposure under study was performed in UKB participants, which was also our analytical sample. However, below we detail in Sensitivity Analyses the strategy we undertook to mitigate this sample overlap.

\section{Genotyping and quality control (QC) in $U K B$}

487,409 UKB participants were genotyped using one of two customised genome-wide arrays that were imputed to a combination of the UK10K, 1000 Genomes Phase 3 and the Haplotype Reference Consortium (HRC) reference panels, which resulted in 93,095,623 autosomal variants [20]. We then applied additional variant level QC and excluded genetic variants with: Fisher's exact test $<0.3$, minor allele frequency (MAF) $<1 \%$ and a missing call rate of $\geq 5 \%$. Individual-level QC meant that we excluded participants with: excessive or minimal heterozygosity, more than 10 putative third-degree relatives as per the kinship matrix, no consent to extract DNA, sex mismatches between self-reported and genetic sex, missing QC information and non-European ancestry (based on how individuals had self-reported their ancestry and the similarity with their genetic ancestry, as per a principal component analysis of their genotype).

\section{Outcomes: cognitive function measures}

At baseline UKB administered a total of five cognitive assessments to all participants, via a computerised touch-screen interface, all of which are described in detail elsewhere [21]. For the purposes of this study and to maximise statistical power, we pragmatically chose visual memory and reaction time. For the visual memory task respondents were asked to correctly identify matches from six pairs of cards after they had memorised their positions. The number of incorrect matches (number of attempts made to correctly identify the pairs) was then recorded, with a greater number reflecting poorer visual memory. Reaction time (in milliseconds) was recorded as the mean time taken by participants to correctly identify matches in a 12-round game of the card game 'Snap'. A higher score on this test indicated a slower (poorer) reaction time. Both of these variables were positively skewed and therefore, reaction time scores were transformed using the natural logarithmic function $[\ln (\mathrm{x})]$, whilst visual memory was transformed using $[\ln (x+1)]$. 
medRxiv preprint doi: https://doi.org/10.1101/2021.09.28.21264215; this version posted September 29, 2021. The copyright holder for this preprint (which was not certified by peer review) is the author/funder, who has granted medRxiv a license to display the preprint in

\section{Selection of genetic instruments}

\section{Main daytime napping genetic instrument}

Daytime napping was instrumented using 123 genome-wide significant $(\mathrm{p}<5 * 10-8)$ genetic variants discovered in a recent genome-wide association study (GWAS) [22]. These variants were discovered in 452,633 UKB participants, based on the question 'Do you have a nap during the day?' administered at baseline, with possible responses Never/rarely, Sometimes and Usually (Prefer not to answer was coded as missing in the GWAS). Thirty-eight percent of UKB respondents reported that they 'sometimes' napped and 5\% reported that they 'usually' have a nap. The 123 variants explain $1 \%$ of the variance in daytime napping. However, here we selected 92 of the 123 daytime napping SNPs, as we used linkage disequilibrium (LD) clumping in PLINK with $\mathrm{r}^{2}<0.01$ within $250 \mathrm{~kb}$. We then calculated the F-statistic which yielded $\mathrm{F}=41$ using the Cragg-Donald formula [23]:

$$
F=\left(\frac{\mathrm{n}-\mathrm{k}-1}{\mathrm{k}}\right)\left(\frac{R^{2}}{1-R^{2}}\right)
$$

We harmonised the genetic variants between the exposure GWAS and our outcome sample by aligning effect alleles and we also excluded palindromic SNPs. Our instrument selection process is detailed in Supplementary Figure S1.

\section{Additional daytime napping genetic instruments}

We additionally partitioned the daytime napping instrument into two further sub-instruments: i) an 86-SNP instrument which consists of those SNPs that remained genome-wide significant when in the published GWAS the authors excluded individuals who had sleep apnoea $(\mathrm{n}=5553)$, ii) a 47-SNP instrument which comprised SNPs that remained genome-wide significant on adjustment for excessive daytime sleepiness. Using the formula $\mathrm{F}=\left(\boldsymbol{\beta}^{2} / \mathrm{SE}^{2}\right)$ to approximate average instrument strength for these additional instruments in sensitivity analyses, we calculated the F-statistic for each of these additional instruments, which yielded $\mathrm{F}=98.1$ and $\mathrm{F}=47.0$, respectively indicating good instrument strength.

\section{Statistical analyses}

\section{i. $\quad$ Main analyses}

Using PLINK 2.0 we performed linear regressions between each of the daytime napping genetic variants and our outcomes, adjusting for 10 principal components to minimise issues of residual confounding by population stratification. For our 
medRxiv preprint doi: https://doi.org/10.1101/2021.09.28.21264215; this version posted September 29, 2021. The copyright holder for this preprint (which was not certified by peer review) is the author/funder, who has granted medRxiv a license to display the preprint in

It is made available under a CC-BY-NC-ND 4.0 International license.

MR analyses, inverse-variance weighted (IVW) MR was implemented, with standard sensitivity analyses including MR-Egger and the Weighted Median Estimator (WME). The IVW, also known as 'conventional MR' estimates the effect of an exposure (e.g. daytime napping) on a given outcome (e.g. visual memory/reaction time) by taking an average of the genetic variants' ratio of variant-outcome $(S N P \rightarrow Y)$ to variant-exposure $(S N P \rightarrow X)$ association, which is calculated using the principles of a fixed-effects meta-analysis [24]. MR-Egger regression (which yields an intercept term to denote the presence or absence of unbalanced horizontal pleiotropy) [25] and the WME can give more robust estimates when up to $50 \%$ of the genetic variants are invalid and thus, do not meet all MR assumptions [26]. Results are expressed as expß-coefficients for log-transformed outcomes, which should be interpreted as \% differences in the outcome for every 1-unit increase in daytime napping frequency.

ii. $\quad$ Sensitivity analvses

a. To ensure that our results were robust we performed all of our MR analyses additionally using a 47-SNP and 86-SNP daytime napping instrument, as described earlier. We confirmed a priori before implementing our analyses that these instruments were of adequate strength (via F-statistics).

b. To mitigate potential issues with sample overlap between the discovery GWAS for daytime napping and our analytical dataset (both used UKB) we additionally performed our MR analyses using a reduced 17-SNP daytime napping instrument. This instrument consisted of the SNPs that were replicated $\left(\right.$ at $\left.p<5^{*} 10^{-8}\right)$ [22] in an independent cohort (23andMe, $N=541,333)$, as an a priori F-statistic confirmed that it was suitable for use in our MR analyses ( $F=67.1)$.

iii. $\quad$ Testing of MR assumptions

a. Associations between genetic instrument and exposure instrumented: GWAS robust: this assumption was met, as the daytime napping variants we instrumented here have been robustly associated with this phenotype in a recent very large-scale GWAS.

b. No evidence of horizontal pleiotropy (no association between genetic instruments and the outcome, other than via the exposure under study): we 
medRxiv preprint doi: https://doi.org/10.1101/2021.09.28.21264215; this version posted September 29, 2021. The copyright holder for this preprint (which was not certified by peer review) is the author/funder, who has granted medRxiv a license to display the preprint in

It is made available under a CC-BY-NC-ND 4.0 International license

tested this assumption by implementing MR-Egger and WME sensitivity analyses, as detailed above.

c. No associations between genetic variants and confounders of the relationship under study: to assess this assumption we regressed a number of common confounders on our main instrument (92 SNPS) and used a Bonferroni multiple testing correction of 0.05/92=0.0005. The list of confounders we selected was based on recent literature [8] and included: years of full-time education, deprivation (Townsend deprivation quintiles), smoking (ever/never/ex-smoker), physical activity (days of moderate activity for more than 10 minutes), body mass index (BMI) $\left(\mathrm{kg} / \mathrm{m}^{2}\right)$, alcohol consumption (1-8 times per month/16 times per month-daily/rarely or never), prevalent type-2 diabetes (No/Yes), prevalent hypertension (No=not on antihypertensive medication, Yes=on antihypertensive medication), prevalent cardiovascular disease (No/Yes).

\section{Results}

Sample characteristics

In our sample $53 \%$ of participants were female with a mean age of 57 years, spent an average of 15 years in full-time education and $22 \%$ were in the most deprived quintile. The mean reaction time was 555 milliseconds and the mean number of visual memory errors recorded was 4 , while average BMI was $27.3 \mathrm{~kg} / \mathrm{m}^{2}$. At baseline, there were 20,228 participants with diabetes, 29,747 with CVD, 93,092 on antihypertensive medication. Fifty per cent reported consuming alcohol between 16 times per month-daily. Participants did an average of 3.6 days of moderate physical activity for more than 10 minutes and $27 \%$ reported ever smoking.

\section{Main MR results}

Associations between davtime napping and cognitive function using a 92-SNP genetic $\underline{\text { instrument }}$

Figures 1 and 2 shows that using our 'Main' instrument we found no associations between daytime napping and reaction time or visual memory. We also found no evidence of horizontal pleiotropy using MR-Egger and WME approaches (all MR-Egger intercept p-values $>0.05)$. 
medRxiv preprint doi: https://doi.org/10.1101/2021.09.28.21264215; this version posted September 29, 2021. The copyright holder for this preprint (which was not certified by peer review) is the author/funder, who has granted medRxiv a license to display the preprint in

It is made available under a CC-BY-NC-ND 4.0 International license .

Associations between daytime napping and cognitive function using a 47- and 86-SNP genetic instrument

As results reported in Figures 1 and 2, sensitivity analyses using a 47-SNP instrument (adjusted for excessive daytime sleepiness) also showed no associations with reaction time or visual memory. Similar results emerged for the 86-SNP instrument (excluding individuals with self-reported sleep apnoea) with no evidence of associations with either of the two cognitive function measures. For reaction time the MR-Egger intercept $\mathrm{p}$-value indicated the presence of unbalanced horizontal pleiotropy using both the 47- and 86-SNP instruments. Thus, we excluded one SNP that was the most strongly associated with reaction time (rs2099810), re-ran our MR analyses and the MR-Egger intercept had p>0.05. The MR-Egger slopes, as well as the IVW and WME results, remained unchanged and are therefore not presented. However, we did not detect any issues with horizontal pleiotropy for visual memory, with both MR-Egger intercept p-values $>0.05$.

Association between davtime napping and cognitive function using a 17-SNP instrument with no sample overlap

Using this restricted instrument to ensure no overlap between our exposure and outcome samples, across all three MR approaches we observed no associations with reaction time or visual memory. MR-Egger detected no issues with unbalanced horizontal pleiotropy $(\mathrm{p}>0.05)$. Results are presented in Figures 1 and 2.

\section{Testing MR Assumption III}

Associations between our main 92-SNP davtime napping genetic instrument and common confounders

After a Bonferroni correction we observed that 12 variants were associated with education, two with deprivation, four with smoking, two with physical activity, 19 with BMI, one with alcohol consumption, three with diabetes, eight with hypertension and one with CVD. We present these associations in Supplementary Table 3.

Figure 1. Associations between daytime napping and reaction time in UKB including sensitivity analyses 
medRxiv preprint doi: https://doi.org/10.1101/2021.09.28.21264215; this version posted September 29, 2021. The copyright holder for this preprint (which was not certified by peer review) is the author/funder, who has granted medRxiv a license to display the preprint in It is made available under a CC-BY-NC-ND 4.0 International license.

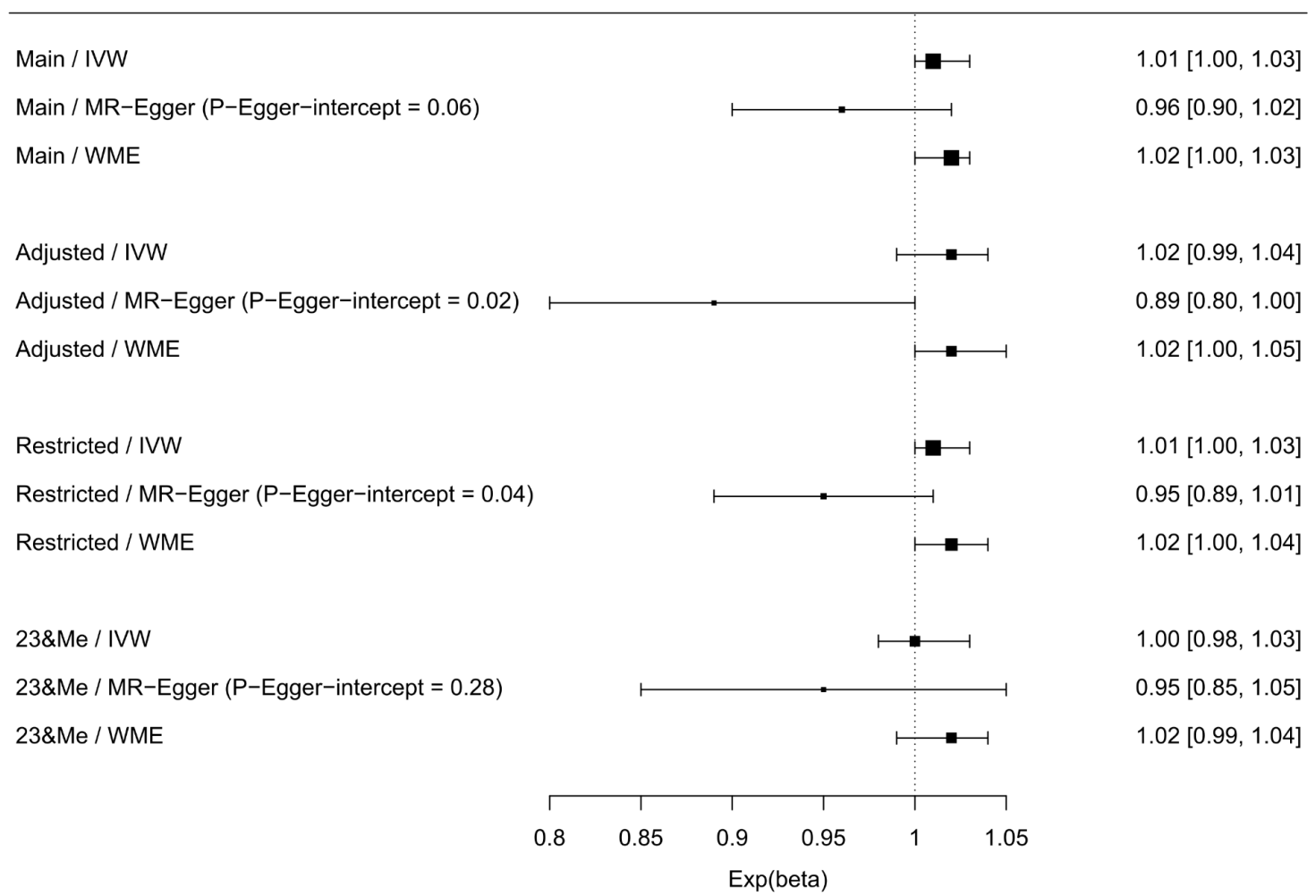

Note. $\mathrm{N}=378,932$, instrument details: Main=92-SNP main daytime napping instrument from Dashti et al, 2021, Adjusted=47-SNP instrument adjusted for excessive daytime sleepiness, Restricted $=86$-SNP instrument excluding individuals with self-reported sleep apnoea, $23 \& \mathrm{Me}=17-\mathrm{SNP}$ instrument used as it has no sample overlap with UKB. IVW=inverse-variance $\quad$ weighted， $\quad \mathrm{WME}=$ weighted median estimator， $95 \% \mathrm{CI}=95 \%$ confidence interval. $\operatorname{Exp}($ beta): exponentiated beta (e.g. an exponentiated beta of 1.01 in reaction time represents an estimated $1 \%$ increased/slower reaction time for every 1-unit increase in daytime napping frequency).

Figure 2. Associations between daytime napping and visual memory in UKB including sensitivity analyses 
medRxiv preprint doi: https://doi.org/10.1101/2021.09.28.21264215; this version posted September 29, 2021. The copyright holder for this preprint (which was not certified by peer review) is the author/funder, who has granted medRxiv a license to display the preprint in

It is made available under a CC-BY-NC-ND 4.0 International license

Visual Memory

Estimate $[95 \% \mathrm{Cl}]$

Main / IVW
Main / MR-Egger (P-Egger-intercept = 0.40)
Main / WME
Adjusted / IVW
Adjusted / MR-Egger (P-Egger-intercept = 0.44)
Adjusted / WME
Restricted / IVW
Restricted / WME / MR-Egger (P-Egger-intercept = 0.42)
23\&Me / IVW
23\&Me / MR-Egger (P-Egger-intercept = 0.18)

$0.99[0.94,1.05]$
$0.91[0.74,1.12]$
$0.97[0.91,1.03]$
$1.00[0.92,1.09]$
$0.87[0.60,1.25]$
$0.99[0.91,1.08]$
$0.99[0.94,1.05]$
$0.91[0.74,1.13]$
$0.97[0.91,1.04]$
$1.00[0.90,1.12]$
$0.76[0.52,1.15]$
$0.98[0.89,1.10]$

Note. $\mathrm{N}=378,932$, instrument details: Main=92-SNP main daytime napping instrument from Dashti et al, 2021, Adjusted=47-SNP instrument adjusted for excessive daytime sleepiness, Restricted $=86-$ SNP instrument excluding individuals with self-reported sleep apnoea, $23 \& \mathrm{Me}=17-\mathrm{SNP}$ instrument used as it has no sample overlap with UKB. $\mathrm{IVW}=$ inverse-variance $\quad$ weighted， $\mathrm{WME}=$ weighted median estimator， $95 \% \mathrm{CI}=95 \%$ confidence interval. $\operatorname{Exp}($ beta): exponentiated beta.

\section{Discussion}

Using a comprehensive Mendelian randomisation design, we show no evidence of associations between self-reported habitual daytime napping and reaction time, or visual memory in the UK Biobank.

To our knowledge, no prior studies have used MR to try to disentangle the relationship between daytime napping and cognitive function. Nonetheless, a recent MR study found tentative evidence that daytime napping may reduce AD risk [16]. Furthermore, previous MR studies have found that sleep duration is causally associated with cognitive function [14] and AD risk [15]. Despite evidence of cross-sectional associations between daytime napping and cognitive outcomes [7,8], and the relationship between cognitive function and AD [27], we 
medRxiv preprint doi: https://doi.org/10.1101/2021.09.28.21264215; this version posted September 29, 2021. The copyright holder for this preprint (which was not certified by peer review) is the author/funder, who has granted medRxiv a license to display the preprint in

It is made available under a CC-BY-NC-ND 4.0 International license

expected to find a causal link between daytime napping and reaction time, or visual memory. However, we found no evidence to support this hypothesis.

More reliable cognitive measures may be required to identify these effects. In this regard, our results may be influenced by test characteristics (e.g., task sensitivity and difficulty, timing, or instructions) [3]. Furthermore, UKB cognitive assessments are not standardised and were designed specifically for this cohort. However, it is important to establish that, despite these limitations, UKB cognitive data is a valuable resource for researchers seeking determinants of cognitive function [21].

Moreover, individual differences in the experiences with napping, for example, the presence of sleep apnoea [28] and daytime sleepiness [3], may affect the degree of the cognitive benefit generated by naps. In this regard, we partitioned the daytime napping instrument into two sub-instruments (one excluding individuals who had sleep apnoea and the other adjusting for excessive daytime sleepiness). Still, no evidence of associations between self-reported daytime napping and reaction time, or visual memory was found. However, other factors such as slow waves production, the quality of the prior sleep period or the presence of sleep inertia could also influence napping restoration [3], which could lead to different effects on cognition. The association between napping and cognitive function may also be influenced by depression, as the frequency of napping has been associated with depressive symptoms $[7,29,30]$. Also, the relationship between depression and cognition is well established $[31,32]$.

In addition, we only analysed the frequency of napping. However, observational studies have shown that the length and timing of naps could also affect cognitive function [10]. Unfortunately, information on these dimensions is not available in UKB. Regarding length, previous studies reported that, unlike long naps, the beneficial effects of brief naps are evident almost immediately after waking but last for a shorter period of time [10]. Nap's timing also determines its effect on cognition, with the post-lunch dip period being the most favourable time to take a nap to overcome the temporary drop in alertness and performance evidence during this period [33].

To validate our MR findings, it was checked that the three core assumptions that underlie MR were met. Assumption I was met as we instrumented the best available genetic variants as they have been robustly associated with daytime napping in a recent large-scale GWAS [22]. MR-Egger and WME sensitivity analyses were implemented to check assumption II. No 
medRxiv preprint doi: https://doi.org/10.1101/2021.09.28.21264215; this version posted September 29, 2021. The copyright holder for this preprint (which was not certified by peer review) is the author/funder, who has granted medRxiv a license to display the preprint in

It is made available under a CC-BY-NC-ND 4.0 International license.

evidence of horizontal pleiotropy was found, which corroborates that the association between our genetic variants (for the exposure) and outcomes were only via the exposure under study. Finally, assumption III was tested by performing regressions between our genetic instruments and unobserved confounders, and we found that some of the variants were associated with common confounders. These associations should be further investigated, as they may constitute vertical, rather than horizontal pleiotropy.

\section{Limitations}

Limitations of the study should be noted. First, our exposure and outcome samples overlapped by $77 \%$. However, sensitivity analyses using a reduced $17-$ SNP daytime napping instrument, replicated by the GWAS authors [22] in an independent cohort (23andMe), confirmed that it was suitable for use in our MR analyses. Using this reduced instrument, we observed no associations with reaction time or visual memory. Second, participants were only white European; future work should examine if these findings are replicated in other ancestries. Third, future instruments for the length and timing of daytime napping are necessary. Fourth, another limitation of our study was the self-report nature of the exposure under study, but napping is notoriously difficult to measure using objective methods. However, in UKB there was consistency between self-reported sleep measures and accelerometer-derived daytime inactivity duration, which increases confidence in the SNPs for daytime napping.

\section{Conclusions}

In summary, our Mendelian randomisation study of daytime napping and reaction time, and visual memory suggests that these associations are not likely to be causal. The lack of evidence for an association in the present study may indicate that other cognitive outcomes (e.g. alertness) may be affected by habitual daytime napping and should be studied in the future.

\section{Acknowledgements}

This work was conducted under the approved UK Biobank project number 71702. We thank all UKB researchers and volunteers.

\section{Declaration of Sources of Funding}


medRxiv preprint doi: https://doi.org/10.1101/2021.09.28.21264215; this version posted September 29, 2021. The copyright holder for this preprint (which was not certified by peer review) is the author/funder, who has granted medRxiv a license to display the preprint in It is made available under a CC-BY-NC-ND 4.0 International license.

This work was supported by Programa de Desarrollo de las Ciencias Básicas (PEDECIBA, MEC-UdelaR, Uruguay) [to VP]; Agencia Nacional de Investigación e Innovación (ANII, Uruguay) [grant number MOV_CA_2020_1_163153 to VP]; Comisión Sectorial de Investigación Científica (CSIC, UdelaR, Uruguay) [to VP]; Comisión Académica de Posgrados (CAP, UdelaR, Uruguay) [to VP]; National Heart, Lung, and Blood Institute (NHLBI) [grant number K99HL153795 to HSD]; Diabetes UK and British Heart Foundation [grant number $15 / 0005250$ to $\mathrm{VG}$ ].

\section{Author contributions}

Literature search: VP. Study design: VG. Data analysis: VG. Data interpretation: VG, VP, HSD. Writing the manuscript: VG and VP. Revision of the manuscript: VG, VP, HSD.

\section{Conflict of Interest}

The authors declare that they have no conflict of interest.

\section{References}

1. Dhand R, Sohal H. Good sleep, bad sleep! The role of daytime naps in healthy adults. Curr Opin Pulm Med 2006;12:379-82.

2. Faraut B, Andrillon T, Vecchierini M-F et al. Napping: A public health issue. From epidemiological to laboratory studies. Sleep Med Rev 2017;35:85-100.

3. Milner CE, Cote KA. Benefits of napping in healthy adults: impact of nap length, time of day, age, and experience with napping. J Sleep Res 2009;18:272-81.

4. Zhang Z, Xiao X, Ma W et al. Napping in Older Adults: a Review of Current Literature. Curr Sleep Med Rep 2020;6:129-35.

5. Leng Y, Wainwright N, Cappuccio F et al. To nap or not to nap: evidence on daytime napping and increased 13-year mortality in a British population. Sleep Med 2013;14:e25.

6. Zhong $\mathrm{G}$, Wang $\mathrm{Y}$, Tao $\mathrm{T}$ et al. Daytime napping and mortality from all causes, cardiovascular disease, and cancer: a meta-analysis of prospective cohort studies. Sleep Med 2015;16:811-9.

7. Cross N, Terpening Z, Rogers NL et al. Napping in older people 'at risk' of dementia: relationships with depression, cognition, medical burden and sleep quality. $J$ Sleep Res 2015;24:494-502. 
medRxiv preprint doi: https://doi.org/10.1101/2021.09.28.21264215; this version posted September 29, 2021. The copyright holder for this preprint (which was not certified by peer review) is the author/funder, who has granted medRxiv a license to display the preprint in It is made available under a CC-BY-NC-ND 4.0 International license .

8. Leng Y, Redline S, Stone KL et al. Objective napping, cognitive decline, and risk of cognitive impairment in older men. Alzheimers Dement 2019;15:1039-47.

9. Ficca G, Axelsson J, Mollicone DJ et al. Naps, cognition and performance. Sleep Med Rev 2010;14:249-58.

10. Lovato N, Lack L. The effects of napping on cognitive functioning. In: Kerkhof GA, Dongen HPA van (eds.). Progress in Brain Research. Vol 185. Elsevier, 2010, $155-66$.

11. Cai H, Su N, Li W et al. Relationship between afternoon napping and cognitive function in the ageing Chinese population. Gen Psychiatry 2021;34:e100361.

12. Smith GD. Mendelian randomization: prospects, potentials, and limitations. Int $J$ Epidemiol 2004;33:30-42.

13. Smith GD, Ebrahim S. 'Mendelian randomization': can genetic epidemiology contribute to understanding environmental determinants of disease? Int $J$ Epidemiol $2003 ; 32: 1-22$.

14. Henry A, Katsoulis M, Masi S et al. The relationship between sleep duration, cognition and dementia: a Mendelian randomization study. Int J Epidemiol 2019;48:849-60.

15. Grover S, International Age-related Macular Degeneration Consortium (IAMDGC), Sharma M. Sleep, Pain, and Neurodegeneration: A Mendelian Randomization Study. Neurology, 2021.

16. Anderson EL, Richmond RC, Jones SE et al. Is disrupted sleep a risk factor for Alzheimer's disease? Evidence from a two-sample Mendelian randomization analysis. Int J Epidemiol 2021;50:817-28.

17. Blazer DG, Yaffe K, Karlawish J. Cognitive Aging: A Report From the Institute of Medicine. JAMA 2015;313:2121-2.

18. $\mathrm{Hu} \mathrm{C}, \mathrm{Yu} \mathrm{D}$, Sun $\mathrm{X}$ et al. The prevalence and progression of mild cognitive impairment among clinic and community populations: a systematic review and meta-analysis. Int Psychogeriatr 2017;29:1595-608.

19. Sudlow C, Gallacher J, Allen N et al. UK Biobank: An Open Access Resource for Identifying the Causes of a Wide Range of Complex Diseases of Middle and Old Age. PLOS Med 2015;12:e1001779.

20. Bycroft C, Freeman C, Petkova D et al. The UK Biobank resource with deep phenotyping and genomic data. Nature 2018;562:203-9.

21. Lyall DM, Cullen B, Allerhand M et al. Cognitive Test Scores in UK Biobank: Data Reduction in 480,416 Participants and Longitudinal Stability in 20,346 Participants. PLOS ONE 2016;11:e0154222. 
medRxiv preprint doi: https://doi.org/10.1101/2021.09.28.21264215; this version posted September 29, 2021. The copyright holder for this preprint (which was not certified by peer review) is the author/funder, who has granted medRxiv a license to display the preprint in It is made available under a CC-BY-NC-ND 4.0 International license.

22. Dashti HS, Daghlas I, Lane JM et al. Genetic determinants of daytime napping and effects on cardiometabolic health. Nat Commun 2021;12:900.

23. Burgess S, Thompson SG, CRP CHD Genetics Collaboration. Avoiding bias from weak instruments in Mendelian randomization studies. Int J Epidemiol 2011;40:755-64.

24. Burgess S, Bowden J. Integrating summarized data from multiple genetic variants in Mendelian randomization: bias and coverage properties of inverse-variance weighted methods. ArXiv151204486 Stat 2015.

25. Bowden J, Davey Smith G, Burgess S. Mendelian randomization with invalid instruments: effect estimation and bias detection through Egger regression. Int $J$ Epidemiol 2015;44:512-25.

26. Bowden J, Smith GD, Haycock PC et al. Consistent Estimation in Mendelian Randomization with Some Invalid Instruments Using a Weighted Median Estimator. Genet Epidemiol 2016;40:304-14.

27. Silva MVF, Loures C de MG, Alves LCV et al. Alzheimer's disease: risk factors and potentially protective measures. J Biomed Sci 2019;26:33.

28. Masa JF, Rubio M, Pérez P et al. Association Between Habitual Naps and Sleep Apnea. Sleep 2006;29:6.

29. Stone KL, Ewing SK, Ancoli-Israel S et al. Self-Reported Sleep and Nap Habits and Risk of Mortality in a Large Cohort of Older Women. J Am Geriatr Soc 2009;57:604-11.

30. Liu Y, Peng T, Zhang S et al. The relationship between depression, daytime napping, daytime dysfunction, and snoring in 0.5 million Chinese populations: exploring the effects of socio-economic status and age. BMC Public Health 2018;18:759.

31. Gotlib IH, Joormann J. Cognition and Depression: Current Status and Future Directions. Annu Rev Clin Psychol 2010;6:285-312.

32. Rock P, Roiser J, Riedel W et al. Rock PL, Roiser JP, Riedel WJ, Blackwell AD. Cognitive impairment in depression: a systematic review and meta-analysis. Psychol Med 2013;44:1-12.

33. Slama H, Deliens G, Schmitz R et al. Afternoon Nap and Bright Light Exposure Improve Cognitive Flexibility Post Lunch. PLOS ONE 2015;10:e0125359. 